\title{
Team Characteristics, Peer Competition Threats And Individual Performance Within a Working Team: An ANALysis of Realtor AgENTS
}

\author{
Chung Chan Lee \\ National Pingtung Institute of Commerce, Department of Real Estate Management, Taiwan
}

Accepted: July 2013

\begin{abstract}
This paper uses survey data from a questionnaire for brokers given to Kaohsiung realtors in order to explore the effect of the threat of peer competition on an individual's performance. In the empirical model, the branch "average performance of other agents" is used as the proxy variable for peer competition, and the hierarchical linear modeling (HLM) model is applied for estimation. The empirical results suggest that the average performance by other agents has a significant negative effect on an individual's performance. In branches that have more "agents" or have a "team compensation scheme", the effect of other agents' average performance on an individual's performance is significantly higher than that for the branches with fewer "agents" or without a "team compensation scheme". These findings are consistent with theoretical expectations.
\end{abstract}

Key words: individual performance, team compensation scheme, peer competition threat, hierarchical linear modeling

JEL: J101, 131, 133

1

\section{Introduction}

Early organizational management literature often uses human capital models to verify the impact of education and work experience on an individual's income. Empirical results suggest that education and work experience have a positive impact on an individual's income (for example, Mincer, 1970, 1974; Mincer \& Polachek, 1974). Follain, Lutes and Meier (1987) studied the income of realtors at an earlier stage in real estate research. Glower and Hendershott (1988); Crellin, Frew and Jud (1988); Jud and Winkler (1988); and Sirmans and Swicegood $(1997,2000)$ also discussed the topic. More recently, Benjamin, Jud and Sirmans (2000) provided a comprehensive review of these works and summarized them in tabular form. ${ }^{1}$

In addition to these discussions on labor capital's effect on job performance, the impact of incentives has also become an important labor economics topic in recent years (Baron \& Kreps, 1999; Lazear, 1998). Lazear (1999) has indicated that, owing to the challenges in accessing data, most discussions have been purely theoretical, with studies from an empirical perspective remaining limited. The research topics have related to "individual performance" measures (relevant studies include those by Paarsch and Shearer (1999, 2000), Booth and Frank (1999), and Lazear (2000)). Drago and Garvey (1998) conducted an empirical study on the interactive relationships among members of a working team. However, empirical analysis of the interactive relationships among working team members is, generally speaking, under continuous analysis and development. At present, there is no literature examining real estate agents' performance using the concept of the working team.

Kandel and Lazear (1992) noted that, in a working team, the team's norms may be established by peer pressure aimed at enhancing the team's overall performance. Lazear (1998) argued that members of a corporate organization could form a working team. The interactive relationships among team members often have a significant impact on the team's output. Thus, if team compensation schemes are adopted in the corporate organization, team 
performance is expected to be enhanced; moreover, a large company size is also expected to increase team performance. Crellin, Frew and Jud (1988) suggested that a larger company size and a higher number of sales agents results in higher incomes for the latter. Notably, however, team cooperation may reduce individual working motivation and create social loafing behavior, as team members come to expect more from other employees (Karau \& Wlliams, 1993). Lazear (1998) has noted that, although team compensation schemes may improve team performance, they may also result in a freeriding problem by reducing individual employees' work incentives. Teamwork's impact on a team's performance has been the focus of previous studies and discussions (Kandel \& Lazear, 1992; Crellin, Frew \& Jud, 1988; Karau $\&$ Wlliams, 1993). From the perspective of individual performance, an increase in the number of sales agents increases the level of competition for business among the agents, possibly resulting in a negative impact on individual performance.

According to Kandel and Lazear (1992), when the "average performance of others in the team" increases, it will stimulate the individual performance of each team member. When the average peer performance improves, individuals will be encouraged via peer pressure to improve their own performance. When the team compensation ratio is higher, others' average performance will have a greater impact on individual performance. Kandel and Lazear grounded their proposals in theoretical analysis. Although they used Japanese general manufacturers as their example, they did not empirically test their theories. Therefore, whether or not their theories are applicable to the housing brokerage industry, with its competitive and cooperative peer structure and its emphasis on individual performance, is a subject open to empirical testing.

In addition, the housing brokerage industry emphasizes individual performance and team cooperation. In Taiwan, the salary structure at real estate brokerage companies typically involves an individual performance-based salary, with some companies also providing team bonuses. Peer working relations demonstrate the competitive relationships among members of the corporate organization. With limited resources, peers may strive for business opportunities. According to this study's survey, 55 per cent of the respondents report that peers have competed with them for business cases in the past. ${ }^{2}$ The "average performance of other agents" may therefore imply active peer competition over cases, a phenomenon which can cause negative individual performance. In brokerage companies with a team compensation scheme, there will be fewer visible problems related to free-riding and social loafing. If the average performance by others is relatively better, this will highlight the performance of other team members and possibly strengthen the competition threat for individuals.

Although some empirical studies in educational economics and regional economics use the peer effect as the topic of analysis, there are few empirical analyses of the impact of peer competition on an individual's performance in real estate studies. The housing brokerage industry itself emphasizes individual performance and team cooperation, as well as competition. Hence, understanding the impact of the peer competition threat on the individual performance by realtors is a topic for further analysis and discussion.

The main purposes of this study are as follows: (1) to discuss whether the average performance of others (representing a peer competition threat) has any negative impact on an individual's performance; (2) to discuss whether more agents or a team compensation scheme lead to lower individual performances; and (3) to discuss whether the marginal effect of the average performance by others on individual performance increases with a greater number of agents or with a team compensation scheme.

As individual agents are nested in brokerage branches, the research data for this study has a nested structural relationship. Using the traditional OLS for estimation may violate the error term independence homogeneity assumption (Raudenbush \& Bryk, 2002). This paper thus applies a two-level linear model for estimation.

This paper is organized into the following six sections: Section 1 is the introduction; Section 2 presents the literature review; Section 3 describes the research method and empirical model structure; Section 4 explains the data source and variable setting; Section 5 contains 
the empirical results and analysis; and Section 6 presents conclusions and suggestions.

\section{2}

\section{Literature review}

Traditionally, human capital models are employed to analyze labor income or work performance. Regarding the impact of a peer group on individual behavioral performance, many studies have been conducted in educational economics, regional economics, and other fields in recent years (Case \& Katz, 1991; Evans, Oates \& Schwab, 1992; Norton, Lindrooth \& Ennett, 1998; Gaviria \& Raphael, 2001; McEwan, 2003; Mossholder, Richardson \& Settoon, 2011). After accounting for variables previously shown to factor into earnings, Anderson, Byrd, and Hurst (2012) found that persons entering into real estate directly as a first career and those with experience in sales or retail do significantly better than others with different backgrounds.

Kandel and Lazear (1992) found that when the average performance of others in the team increases, this inspires the individual performance of each team member. In other words, when the average performance of one's peers improves, individuals are encouraged to improve their own performance owing to peer pressure costs. When an individual's performance is higher than the others' average performance, the peers' average performance will increase, thus making the individual's excellent performance appear less significant. Moreover, when the team bonus rate increases, the rising peer pressure leads to a gradient marginal effect of others' average performance on an individual's performance. In other words, when the team bonus rate is relatively higher, the effect of others within the same team's average performance on an individual's performance will be greater. Babcock, Bedard, Charness, Hartman and Royer (2012) found that team rewards can transcend personal rewards. Lee (2012) discussed the impact of compensation schemes on housing agent performance. According to Lee's results, the individual performance of agents under a Type I compensation scheme, which is similar to the Japanese model of a high base salary and a low proportion of compensation based on performance, is not significantly better than the individual performance of agents under a Type
II compensation scheme, which is similar to the American model of zero base salary and a high proportion of compensation based on performance. Corgnet, Hernan-Gonzalez and Rassenti (2013) found that, with the use of team awards, those individuals entrusted by the organization with peer supervision will exert strong peer pressure to bring organizational production levels to a greater level of productivity.

For housing brokerage companies in Taiwan, some individual branches can be regarded as working teams. On a working team (branch), when the performance of an individual agent is superior to that of others on the team, it may mean that the competition among individuals to perform exceptionally is high. Moreover, the survey data from this study suggest that 83 per cent of agents receive an individual performance bonus rate above 50 per cent; and that 55 per cent of agents engage in peer competition for business. These findings suggest that the average performance of other agents in a branch may also imply a peer competition threat. Thus, this study proposes $\mathrm{H} 1$ :

H1: The average performance of other agents in a branch has a significant negative impact on individual performance.

Lazear (1998) argued that the team's job characteristics, incentive mechanisms (e.g., salary structure) design, and team size will all affect the efforts and interactive relationships among team members. Using data from Continental Airlines in the U.S. during the period from 1994 to 1996, Knez and Simester (2001) conducted an empirical study in which they found that a team compensation scheme can improve a company's internal performance. However, Lazear (1998) argued that, while the team compensation scheme may help enhance the team's performance, it may also create a free-rider problem and reduce the work incentives for individual employees. Thus, this study proposes H2:

H2: A team compensation scheme has a significant negative impact on individual performance.

The fierce contention for cases will result in a higher average performance by other agents in a branch and lower individual performance. For brokerage companies with a team compensation 
scheme, if others' average performance is higher, this may indicate that the performance by other agents strengthens the individual competition threat. In other words, the team compensation scheme may lead to the problem of free-riding, thus strengthening the negative marginal effect of others' average performance on an individual's performance. Thus, this study proposes $\mathrm{H} 3$ :

H3: A team compensation scheme has a significant negative impact on the marginal effect of others' average performance [on individual performance].

As the members of the working team are relatively few, it is easier for them to engage in mutual monitoring, rendering the free-rider problem less serious. For a larger team, however, it will cost more to implement monitoring, and it is difficult to supervise members. Meanwhile, individuals receive smaller percentages when sharing the team's rewards. As a result, the free-rider problem will be more serious (Lazear, 1998). Knez and Simester (2001) also discussed the impact of company size on the free-rider problem and found that there was no free-rider effect. ${ }^{3}$ Using an experimental approach, Falk and Ichino (2003) analyzed the performance of employees facing peer pressure. Their research findings suggested that "pair work" had a higher output than "work alone". Moreover, the perceived peer pressure among employees with low productivity was more intense than among employees with higher productivity. In terms of studies on the performance of housing brokerage industry employees, Follain, Lutes and Meier (1987), and Crellin, Frew and Jud (1988) found that realtors earn higher incomes when they belong to a larger company with more agents. From another perspective, if the number of sales personnel is larger, the problems of free riding and social loafing will be more serious, and thus the impact on individual performance will be more negative. This result was also found by Lazear (1998) and Karau and Wlliams (1993). Janhonen and Johanson (2011) further illustrated that the smaller the team size, the more beneficial it will be to the team performance. Thus, this study proposes $\mathrm{H} 4$ and $\mathrm{H} 5$ :

H4: A greater number of agents will have a significant negative impact on individual performance.

H5: A greater number of agents will have a significant negative impact on the marginal effect of others' average performance [on individual performance].

\section{3}

\section{Research method}

\subsection{Hierarchical linear modeling}

Traditionally, an ordinary least squares (OLS) regression model has been used to model individual performance. However, this regression mode does not take advantage of nested data when modeling individual performances. Raudenbush and Bryk (2002) note that previous analyses of multilevel data are vulnerable to problems such as aggregation bias, misestimated standard errors and heterogeneity of regression errors, since an individual agent is not a single object, but is rather an object belonging to a branch and a company organization. Individual agents in the same branch (or organization) share the branch's characteristics; that is, agents share characteristics with each other. Branch-level characteristics, such as the number of employees and the group bonus, will have an impact on samples and will enable the residuals to violate any independent assumption of the regression model, resulting in an overestimation of the error variance and an underestimation of the regression coefficient standard error. In the past, OLS estimates of individual agent performance have often treated the data that pertains to different hierarchical levels (such as branch characteristics and individual characteristics) as a single level. In fact, relationships between individual agent performance and individual agent characteristics must be addressed in different units or organizational levels.

Hierarchical linear modeling (HLM) is a relatively new approach to modeling nested data. Raudenbush and Bryk (2002) outline various applications and statistical techniques associated with the model. HLM can resolve the problems encountered with traditional OLS regression analysis by avoiding misestimates of standard errors, as well as by ignoring the heterogeneity of regression error terms and errors in aggregation. 


\subsection{Traditional regression model}

To create a traditional regression model, the OLS model was first established. With respect to micro-level variables, the dependent variable is individual performance $(Y)$. Explanatory variables include GENDER, EDUCATION (college graduates or above), IHOUR (individual working hours), $O Y$ (average performance of others), HOY (comparison of individual performance and average performance of others), WEXP (work experience), SWEXP (squares of work experience), HOY (the number of brokerage branch agents), and GBON (team compensation scheme). The model settings are as follows:

$$
\begin{aligned}
& Y_{i}=\beta_{0}+\beta_{1} \text { GENDER }_{i}+\beta_{2} \text { EDUCATION }_{i}+\beta_{3} \text { IHOUR }_{i}+\beta_{4} \text { OY }_{i}+\beta_{5} \text { HOY }_{i}+\beta_{6} \text { WEXP }_{i} \\
& +\beta_{7} \text { SWEXP }_{i}+\beta_{8} \text { SIZE }_{i}+\beta_{9} \text { GBON }_{i}+r_{i}, r_{i} \sim N\left(0, \sigma^{2}\right)
\end{aligned}
$$

where the subscript of the variable refers to the $i$ th agent rather than the $j$ th branch, indicating that the traditional regression model has not been set according to the nested structure. Moreover, the error terms of individuals of different levels $i$ are assumed as independent and homogeneous. Hence, the OLS model is used for estimation. In fact, the error terms of individuals of different levels are often not independent and homogeneous, but are homogeneous within the group and heterogeneous between groups. Therefore, in the nested data structure, the OLS model can easily violate the independently, identically distributed assumption.

\subsection{Hierarchical linear modeling}

This paper uses the following three HLM submodels: the null model, the random coefficient regression model, and the intercepts and slopes-as-outcomes model for empirical studies. As for micro-level variables, dependent variables include individual performance (Y); explanatory variables include GENDER, EDUCATION, IHOUR (individual working hours), OY (average performance of others), HOY (comparison of individual and average performance of others), WEXP (work experiences), and SWEXP (squares of work experiences); and branchlevel characteristic variables include SIZE (the number of brokerage branch agents) and GBON (team compensation scheme). The empirical estimation takes the centered grand mean of the continuous variables. The main goals of this study are as follows: (1) to discuss whether the average performance of others (representing the peer competition threat) has a negative impact on individual performance; (2) to discover whether more agents and a team compensation scheme lead to lower individual performance; and (3) to discover whether the marginal effect of the average performance of others on an individual's performance increass when there are more agents or there is a team compensation scheme. The research structure is illustrated below in Figure 1.

\subsubsection{Model 1: Null model}

This method tests whether average individual performance in various branches of Kaohsiung, Taiwan, differ without taking any explanatory variables into consideration. The main purpose of this model is to distinguish between the intra-branch (intra-group) and inter-branch (intergroup) variation in individual performances in an analysis similar to the one-way ANOVA. The model settings are as follows:

Level 1 (micro-level):

$Y_{i j}=\beta_{0 j}+r_{i j}, r_{i} j \sim N\left(0, \sigma^{2}\right)$,

Level 2 (branch-level):

$\beta_{0 j}=Y_{00}+u_{0 j}, u_{0} j \sim N\left(0, \tau_{00}\right)$,

Where $Y_{i j}$ is the performance of the $i$ th agent in branch $j ; \beta_{\mathrm{o} j}$ is the group mean of the performance in the $j$ th branch; $\sigma^{2}$ is the variance of the error term $r_{i j}$ (i.e., variances within groups); $\Upsilon_{00}$ is the grand mean performance for all agents in the sample; and the error term $u_{0 j}$ represents the random effects associated with branch $j$ and is assumed to have a mean zero and a variance of $\tau_{00}$. The null model is derived by adding Eq. (3) to Eq. (2) as follows:

Mixed model: $Y_{i j}=\Upsilon_{00}+u_{0 j}+r_{i j}$. 
Figure 1

Research framework

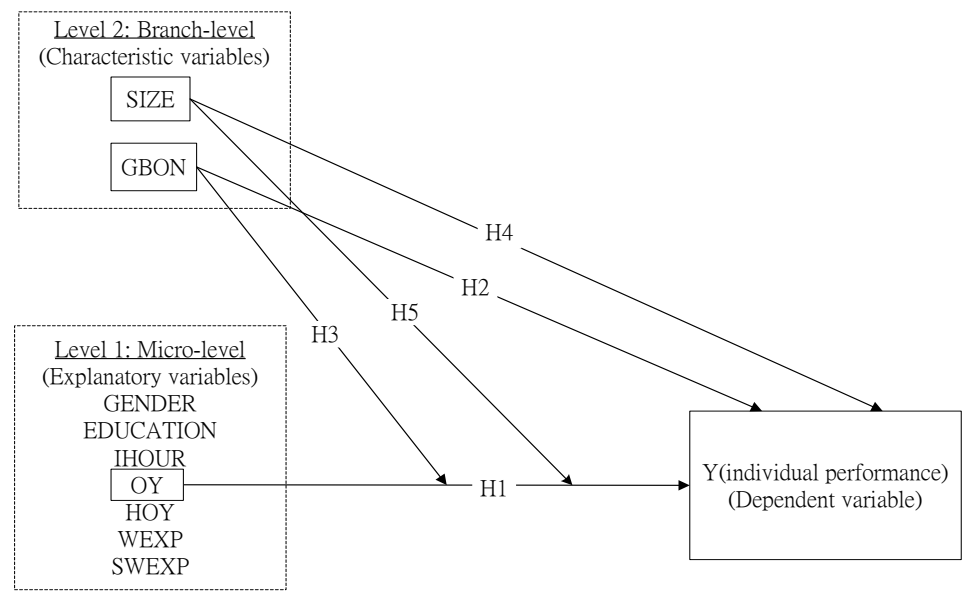

This is the standard one-way ANOVA model with a mean $Y_{00}$, a branch effect $u_{0 j}$ and an individual agent's effect $r_{i j}$. It is therefore possible to treat Eq. (4) as an ANOVA model when examining whether there are variances in the mean performance of respective branches. In other words, the equation is used to validate "the differences between an individual agent's performance and the mean performance of the branches. If the variance between groups or the random component yields a significant test result, the mean performance differs between branches. This means it is necessary to consider the differences between branches. If the test result is not significant, it is acceptable to ignore the differences between these branches. This operation implies that the data can be treated at a single level and can be estimated with Eq. (2). However, if there are differences in the mean performance of the respective branches, it is necessary to use Eq. (4), so that different regression equations are applied to the respective branches.

In the null model, $\operatorname{Var}\left(Y_{i j}\right)=\operatorname{Var}\left(u_{0 j}+r_{i j}\right)=$ $\tau_{00}+\sigma^{2}$. If $\rho=\tau_{00} /\left(\tau_{00}+\sigma^{2}\right) \rho$ is called the intra-class correlation coefficient (ICC) or cluster effect (Raudenbush \& Bryk, 2002). The ICC measures the proportion of variance in the dependent variable that is accounted for by the group (i.e., branch-level or level-2 units). This coefficient shows the proportion of variance in performance that is attributable to differences at a branch level. As soon as the variance of the mean performance for different branches is confirmed, further discussion on the characteristic variables concerning branches, which can explain such a variance, becomes possible.

\subsubsection{Model 2: Random coefficient regression model}

If the null model confirms that the inter-group variation in dependent variables is significant, the explanatory variables of agent characteristics are added at level-1, including GENDER, EDUCATION, IHOUR, OY, HOY, WEXP and $S W E X P$, setting the intercept and slope as random effects. The purpose of doing so is to test whether the variation of intercepts and slopes between groups is significant. The model settings are as follows:

Level 1 (micro-level):

$$
\begin{aligned}
& Y_{i j}=\beta_{0 j}+\beta_{1 j} \text { GENDER }_{i j}+\beta_{2 j} \text { EDUCATION }_{i j}+\beta_{3 j} \text { IHOUR }_{i j}+\beta_{4 j} O Y_{i j}+\beta_{5} H O Y_{i j}+\beta_{6 j} W E X P_{i j}+\beta_{7 j} S W E X P_{i j} \\
& +r_{i j}, r_{i j} \sim N\left(0, \sigma^{2}\right)
\end{aligned}
$$

Level 2 (branch-level):

$$
\beta_{l j}=\gamma_{l 0}+u_{l j}, u_{l j} \sim N\left(0, \tau_{l l}\right), l=0 \sim 7 .
$$

No level-2 explanatory variable (branch characteristics) is added in the random coefficient regression model, and only the impact of level-1 explanatory variables (agent characteristics) on dependent variables is taken 
into consideration. In the proposed model, explanatory variables are added in order to understand whether level-1 explanatory variables have a significant impact on dependent variables. A significant level of random-error variance means the marginal values of level-1 agent characteristics are random and not fixed, indicating that there are other factors causing the differences in agent performance in various branches.

\subsubsection{Model 3: Intercepts and slopes-as- outcomes model}

The intercepts and slopes-as-outcomes model can evaluate whether level-2 characteristic variables can moderate the impact of level-1 explanatory variables on dependent variables. A moderating effect exists between level-2 variables and level-1 variables, so the explanatory power of a level 1 variable can change in strength with a change in a level-2 variable. First, the $S I Z E_{j}$ and $G B O N_{j}$ are specified to influence the intercepts and slopes of the level1 prediction equation. This study attempts to verify, in cases with a team compensation scheme, whether a higher number of agents will lead to a lower level of individual performance (Eq. (8)) and whether the marginal effect of others' average performance on an individual's performance increases in a gradient pattern (Eq. (9)). The settings are as follows:

Level 1 (micro-level):

$$
\begin{aligned}
& Y_{i j}=\beta_{0 j}+\beta_{1 j} \text { GENDER }_{i j}+\beta_{2 j} \text { EDUCATION }_{i j}+\beta_{3 j} \text { IHOUR }_{i j}+\beta_{4 j} O Y_{i j}+\beta_{5} H O Y_{i j}+\beta_{6 j} W E X P_{i j}+\beta_{7 j} S W E X P_{i j} \\
& +r_{i j}, r_{i j} \sim N\left(0, \sigma^{2}\right)
\end{aligned}
$$

Level 2 (branch-level):

$$
\begin{aligned}
& \beta_{0 j}=\gamma_{00}+\gamma_{01} S I Z E_{j}+\gamma_{02} G B O N_{j}+u_{0 j}, u_{0 j} \sim N\left(0, \tau_{00}\right) \\
& \beta_{4 j}=\gamma_{40}+\gamma_{41} S I Z E_{j}+\gamma_{42} G B O N_{j}+u_{4 j}, u_{4 j} \sim N\left(0, \tau_{44}\right) \\
& \beta_{l j}=\gamma_{l 0}+u_{l j}, u_{l j} \sim N\left(0, \tau_{l l}\right), l=1 \sim 3,5 \sim 7 .
\end{aligned}
$$

where, $Y_{01}, Y_{02}$ denote the cross-level direct impact of $S I Z E_{j}$ and $G B O N_{j}$ on individual performance. Statistically significant levels of $\gamma_{41}, \gamma_{42}$ indicate the existence of moderating effects between level-2 variables and level-1 variables; that is, the branch characteristics can moderate the impact of an agent's characteristics on individual performance.

The OLS model assumes that the random errors are homogeneously variant $\left(r_{i} \sim N\left(0, \sigma^{2}\right)\right)$, but HLM allows the random errors to vary between groups (as $r_{i j} \sim N\left(0, \sigma^{2}\right)$ ) in Equation 7 and $u_{i j} \sim N\left(0, \tau_{l l}\right)$ in Equations 8, 9, and 10), suggesting the concept of homogeneity within the group and heterogeneity between groups. The OLS model estimates the intercept and slope by using the fixed effect; hence, the error terms between data groups are not considered (as $u_{l l}$ in Equations 8, 9, and 10). It is therefore unclear whether individual performance varies between branches or whether the impact coefficient of individual level variables on individual performance is random; that is to say, whether or not the coefficient will vary between branches or groups.

\section{4}

\section{Data collection and variable setting}

\subsection{Data collection}

The data in this study is from a questionnaire survey. The questionnaire survey respondents are housing brokerage agents in Kaohsiung, Taiwan (including brokers and sales personnel). The advantages of treating real estate agents as the subject of analysis are as follows: (1) for individual agents, work performance can be measured by the individual's performance without the disruption of uncertain measurements; and (2) the housing brokerage industry usually operates in branches, so the definition of a working team will be more specific.

In Taiwan's brokerage market, brokerage agencies can be divided into chain brokerage agencies and independent agencies. Independent agencies are generally smaller in size and less institutionalized, and are thus often lacking in brand reputation. They are therefore difficult to investigate. Hence, this study used chain brokerage agencies of a larger size (18 
salespeople per branch on average) that were healthy institutions with a better brand image as the survey subjects. The content of the questionnaire was based on the research objective and was modified with reference to past literature and questionnaires (we mainly referred to the study conducted by $\mathrm{Yu} \& \mathrm{Liu}$, 2004; Lee, You \& Shen, 2010). To ensure the validity of the questionnaire, experts and scholars were asked to provide feedback prior to administering the formal survey. The questionnaire was then modified on the basis of the feedback received.

The survey was conducted in October 2011 via mailed questionnaires. The brokerage companies covered in the survey were chain branch companies, such as Pacific Rehouse, Sinyi, 21st Century, U-trust, H\&B Housing, Eastern Realty, China Trust Real Estate, Taiwan Housing, and Yung Ching Realty. This study distributed 867 questionnaires by mail to sales agents in branches of these companies in Kaohsiung and obtained 776 responses. After eliminating responses missing some data, there were 518 valid individual responses, with a valid return rate of 66.7 per cent, including 518 cases with micro-level observation values and 47 branch-level observations. The fitness test of the proportion of the actually recovered samples from various realtor brokers in the population resulted in no significant difference, suggesting that the proportion of actually recovered samples is consistent with the population.

The content of the questionnaire included basic data concerning individual brokerage agents (including gender and educational background), items from the working perspective of the agents (e.g., years of work experience, work performance, number of hours worked), and information on branch characteristics (e.g., the number of sales agents or whether the branch utilizes a team compensation scheme). ${ }^{4}$

Following the non-response bias test process (Armstrong \& Overton, 1977), this study classified all questionnaires collected into either an early or a late group, so as to examine them for significant differences in basic data and research components. Based on a chronological collection time sequence, the 384 questionnaires collected first were labeled as the initial group, while the 134 questionnaires collected later were labeled as the second group. The basic data and research variables for the two groups were compared, and no significant differences were found, indicating that the non-response bias was not a serious issue in this study.

\subsection{Variable setting and explanations}

In this paper, variables are defined as shown in Table 1. As for the explained variables, individual performance is measured with the logarithmic value of the average monthly turnover of the respondent agent for the previous three months. ${ }^{5}$ In housing brokerage companies in Taiwan, the mode of operation is by "branch," and agents of the same branch are regarded as members of a "working team" who have a competitive-cooperative relationship. Hence, variables can be divided into individualrelated explanatory variables and branchrepresenting characteristic variables.

The micro-level explanatory variables include dummy variables, such as the gender and educational level of the agents. If the agent is male, the variable value is set at 1 ; otherwise, the value is set at 0 . If the agent has a collegelevel education or above, the value is set at 1 ; otherwise, it is set at 0 . The respondents' daily average number of hours worked is measured in hourly units by the questionnaire item, "How long was your average working day over the past three months?" Regarding work experience, the questionnaire item, "How long have you been in the housing brokerage industry, including your current job?" is used to measure the years of employment to date.

If the performance of the other agents in the branch is higher, the perceived peer competition threat may be greater. Hence, this study uses the performance of the other agents in the branch as the proxy variable for peer competition threat. "Comparison of individual performance and average performance of others" is used to measure the impact of an individual's performance compared to others' performance. The value is set at 1 if the individual performance is better than others' average performance; otherwise, the value is set at 0 .

The branch-level characteristic variables include the team compensation variable and the number of agents in the branch. Regarding the team compensation variable, this study sets 
the dummy variable as having or not having a team compensation scheme. The value is 1 if the branch provides a team compensation scheme; otherwise, it is set at 0 .

Table 1

Variable descriptions and definitions

\begin{tabular}{|c|c|}
\hline Variable & Operational definition \\
\hline \multicolumn{2}{|c|}{ Level-1 (micro-level) variables } \\
\hline$Y$ & $\begin{array}{l}\text { Individual performance is the logarithm value of the respondent's average monthly sales } \\
\text { performance over the past three months (Unit: NT } \$ 10,000)^{6} ; \text { that is to say, performance } \\
\text { over the period from July to September, } 2011 .\end{array}$ \\
\hline GENDER & If the agent is male, the value is set as 1 ; otherwise, it is set as 0 . \\
\hline EDUCATION & $\begin{array}{l}\text { If the agent has an educational level of college or above, the value is set as } 1 \text {; otherwise, it } \\
\text { is set as } 0 .\end{array}$ \\
\hline IHOUR & $\begin{array}{l}\text { Individual working hours; that is to say, the average number of hours worked by the } \\
\text { respondent every day (unit: hour). }\end{array}$ \\
\hline$O Y$ & $\begin{array}{l}\text { Average performance of others; that is to say, the average performance of other agents in } \\
\text { the same branch. }\end{array}$ \\
\hline$H O Y$ & $\begin{array}{l}\text { Comparison of individual performance and average performance by others. If individual } \\
\text { performance is greater than the average performance of others, it is set as } 1 \text {; otherwise, it } \\
\text { is set as } 0 \text {. }\end{array}$ \\
\hline$W E X P$ & $\begin{array}{l}\text { Work experiences, represented by the number of years working in the housing brokerage } \\
\text { of the agent (unit: year). }\end{array}$ \\
\hline SWEXP & Squares of work experience, as represented by the square of the work-experience variable. \\
\hline \multicolumn{2}{|c|}{ Level-2 (branch-level) variables } \\
\hline$S I Z E_{j}$ & $\begin{array}{l}\text { The number of brokerage branch agents, as represented by the number of agents working } \\
\text { in the same branch. }\end{array}$ \\
\hline$G B O N_{j}$ & $\begin{array}{l}\text { The team compensation scheme is set as a dummy variable. If the branch provides team } \\
\text { compensation, the variable is set as } 1 \text {; otherwise, it is set as } 0 \text {. }\end{array}$ \\
\hline
\end{tabular}

\subsection{Description of sample statistics}

This study processes micro-level and branchlevel descriptive statistics using SPSS19.0 and HLM6.05 for empirical model estimation. The basic statistical characteristics of variables are illustrated in Table 2. Regarding individual characteristics of agents, most of the respondents are male, accounting for 56 per cent of the total (290 people). Respondents with a college education or above account for 43 per cent (223 people). The average daily number of hours worked is 8.93 hours. The average value

Table 2

Micro-level and branch-level descriptive characteristics

\begin{tabular}{|c|c|c|c|c|}
\hline Variables & Mean & S.D. & Min. & Max. \\
\hline \multicolumn{5}{|l|}{ Level-1 (micro-level) variables } \\
\hline$Y$ & 12.60 & 11.82 & 1 & 100 \\
\hline GENDER & 0.56 & -- & 0 & 1 \\
\hline EDUCATION & 0.43 & -- & 0 & 1 \\
\hline IHOUR & 8.93 & 2.37 & 2 & 18 \\
\hline$O Y$ & 12.59 & 5.08 & 25.00 & 4.54 \\
\hline$H O Y$ & 0.415 & -- & 0 & 1 \\
\hline$W E X P$ & 4.76 & 5.39 & 1 & 31 \\
\hline$S W E X P$ & 51.59 & 112.96 & 1 & 961.00 \\
\hline \multicolumn{5}{|l|}{ Level-2 (branch-level) variables } \\
\hline$S I Z E_{i}$ & 18.19 & 8.23 & 5 & 41 \\
\hline$G B O N_{i}$ & 0.33 & -- & 0 & 1 \\
\hline
\end{tabular}


of individual performance is NT\$ 126,000 (exchange rate was US\$ 1 to NT\$ 29.6 in April, 2012); in the same branch, the average individual performance by other agents is NT\$ 125,900 . Agents with an individual performance greater than the average performance by others account for 41.5 per cent (215 people). The average number of years worked is approximately 4.76 years. Regarding branch characteristic variables, branches that provide a team compensation scheme account for 33 per cent of the total (16 branches). In addition, the average number of agents in each branch is approximately 18 people.

\section{5}

\section{Empirical results and analysis}

This paper employs maximum likelihood (ML) to estimate the fixed and random effects of HLM.

\subsection{Model 1: Null model}

Table 3 provides estimates for the null model. The estimate of $\gamma_{00}$ is 0.949 with a standard error of 0.020 . This finding indicates that the mean individual performance is NT\$ 88,920 $\left(=10^{0.949}\right.$, with an exchange rate of US\$ 1 to NT\$ 29.6 in April, 2012). The random effects part shows the decomposition of the variance into its micro-level and branch-level components. The reported $\chi^{2}$ statistic is 77.095 , with 46 degrees of freedom. The results indicate that variance at the branch-level is statistically significant, at a better than the required 5 per cent level of significance. For HLM, the estimate for the branch-level variance is 0.008 ; for the micro-level it is 0.128 . The ICC is $0.008 /$ $(0.008+0.128)=0.059$. For the model, ICC is 0.059 , suggesting that 5.9 per cent of the variance in performances is due to differences at the branch level. That is, individual performance varies across branches. According to the criteria proposed by Cohen (1988), this moderate correlation ICC value suggests that a multilevel model incorporating branch-level and branch characteristics may be useful.

\subsection{Model 2: Random coefficient regression model}

Table 3 shows a partial HLM output for Model

2. The essential components of the fitted multilevel model are the following statistical parameters: the fixed effects regression parameters (gammas), and the variance components for the random effects. In the Model 1 null model, as shown in Table 3, the variance of $r_{i j}$ is 0.128 , and the variance of $r_{i j}$, or the random coefficient regression model of Model 2, is 0.020 , which is a reduction of 84.4 per cent, $\left(R^{2}=(0.128-0.020) / 0.128=0.844\right)$, suggesting that the introduction of micro-level explanatory variables can reduce the variation in individual performance in branches by up to 84.4 per cent. The estimate for $Y_{00}$ is 0.481 (NT\$ $30,269)$. This value is no longer interpreted as the grand mean of performances; instead, it is the expected value of performance when the predictor values are all 0 . The coefficients of GENDER, EDUCATION and IHOUR are not significant, while the coefficients of $O Y, H O Y$, $W E X P$ and $S W E X P$ are at a significant level. For the sake of simplicity, the estimation results are illustrated in Model 3.

The random effects part of the model is concerned with the variance components. As shown in Table 3, the branch's average performance $\beta_{0 j}$ variance $\tau_{00}$, is 1.611 , and it is at a 5 per cent significance level, suggesting that the 47 branches vary significantly in terms of average performance, a finding that is consistent with the conclusions of the null model. The estimates of the variances of $u_{4 j}$, $u_{6 j}, u_{7 j}$ and $\tau_{44}, \tau_{66}, \tau_{66}$, are $0.010,0.0005$, and 0.0001 , respectively, which are at a 5 per cent significance level. This finding indicates that the impact of others' average performance, work experience and squares of work experience on individual performance varies between branches. This result also implies that when neglecting branch characteristics, even after controlling for individual characteristics and job characteristics, the estimated coefficient of individual performance may be biased.

\subsection{Model 3: Intercepts and slopes-as- outcomes model}

Model 3 (Table 3) provides a more complex picture of the effects at the micro-level and branch-level. Concerning fixed effects at the micro-level, in terms of gender, the estimated coefficient value is 0.0143 , which is not significant. When it comes to the impact of gender on performance, conclusions in previous 
studies conflict with each other. For example, the findings by Glower and Hendershott (1988), Crellin, Frew and Jud (1988), Sirmans and Swicegood (1997) and Jud and Winkler (1998) suggest that the working income of female workers is lower. However, Abelson, Kacmar and Jackofsky (1990) argued that the working income of female workers is higher. This paper concludes that men's performance is not significantly higher than women's performance among housing brokerage agents in Kaohsiung, Taiwan. The estimated coefficient of educational level is 0.002 , which is not significant. Education is the investment of human capital. A higher educational level reflects ample knowledge and better performance. However, the empirical results suggest that the educational level has no significant impact on agent performance. A possible explanation for this finding is that housing sales focus on marketing skills and personality. Moreover, continuous on-the-job training has narrowed the gap in terms of the impact of education on agent performance after entering the industry. Regarding daily hours worked, longer daily working hours result in a higher level of effort and better job performance. The estimated coefficient of the daily number of hours worked is 0.004 , which is not significant.

The coefficient estimate of $O Y, \Upsilon_{40}$ is 0.255 , reaching a 5 per cent significance level, indicating that $O Y$ is expected to decrease performance by 25.5 per cent (NT\$ 32,130, calculated using the average performance of the samples). This result suggests that a better performance by others in the branch will result in a larger peer competition threat and that individual performance is expected to suffer, a conclusion that validates the study's expectations. Kandel and Lazear (1992) proposed, from the perspective of theoretical analysis, that the increasing average performance of others in the branch can inspire the individual performance by employees of the branch. They used general manufacturers in Japan as an example, without performing empirical tests. The housing brokerage industry emphasizes individual performance (individuals with compensation rates above 50 per cent account for 83 per cent of the total), implying the existence of a peer competition threat, which has been confirmed in this study. In addition,
Kandel and Lazear (1992) used "the average performance of others" to represent a positive impact on individuals that can inspire working incentives while leaving out nasty peer competition. However, this claim is dubious. ${ }^{7}$

The coefficient estimate of $\mathrm{HOY}, \gamma_{50}$ is 0.172 , reaching a 5 per cent significance level. This result indicates that, if the individual performance is higher than that of the average performance of others in the branch, individual competitiveness is strong. Then, the "individuals of higher performance than the average performance of the peers" will be higher than the "individuals of performance lower than the average peer performance" by 17.7 per cent (NT\$ 22,302), a finding that is consistent with this study's expectations. The coefficient estimate of $W E X P, \Upsilon_{60}$ is 0.014 . The coefficient estimate of $\operatorname{SWEXP}, \gamma_{70}$ is -0.001 . These results are at a 5 per cent level of significance, suggesting that increased work experience can improve an individual's performance but that the effect will gradually diminish with the accumulation of more work experience. This result is consistent with the findings of both Glower and Hendershott (1988) and Sirmans and Swicegood (1997), who suggested that while experience increases the performance of brokers or sales people, beyond a certain point, additional experience is of lesser value.

As far as the cross-level direct effects are concerned, the branch-level coefficient estimate of $S I Z E_{j}, Y_{01}$ is -0.030 and does not reach a 5 per cent significant level. The negative estimation coefficient may be seen from both the branch and individual perspectives. From the branch perspective, the number of agents will affect a branch's performance. More agents lead to a higher branch performance. However, for individuals, increasing the number of agents can potentially increase the problems of freeriding and social loafing, thus having a greater negative impact on an individual's performance. Lazear (1998) argued that larger-sized teams require higher costs in monitoring members, and furthermore that individuals will have a lower share of team returns; thus, the free-rider problem will be more serious. Lazear (1998) further argued that high-tech companies' research and development teams might consist of only 3 to 5 people. As members of the working team are relatively few, it is easier for 
employees to monitor each other and therefore the problem of free-riding is less serious. This study's research suggests that the average number of agents in a branch was approximately 18; furthermore, the largest branch had 41 agents. This number results in higher costs and greater difficulty in implementing monitoring systems, a finding that is consistent with previous studies' findings. The coefficient of the estimation of the number of agents is uncertain. For example, Follain, Lutes, and Meier (1987) and Crellin, Frew, and Jud (1988) found that performance improves with the firm's size, while Sirmans and Swicegood (1997) found no significant relationship between a firm's size and its performance. The branch-level coefficient estimate of $G B O N_{j}, Y_{02}$ is -0.577 and does not reach a 5 per cent significant level. The negative estimate coefficient may indicate the existence of a free-rider problem. This research finding suggests that the number of agents or having a team compensation scheme does not directly affect an individual's performance.

The cross-level moderate effect suggests that the coefficient of the interaction of variables $\gamma_{41}$ is estimated at -0.004 with a 5 per cent significance level. The result of this model shows that $S I Z E_{j}$ has significant cross-level interactions. In other words, having more agents in the branch would strengthen the negative impact of a peer competition threat on an individual's performance, implying that peer competition would be fiercer in cases with limited resources. If performance by others is higher, the impact on the individual's performance will be more adverse. The coefficient of the interaction of variables $\gamma_{42}$ is estimated at 0.086 with a 5 per cent significance level. The results of this model show that $G B O N_{j}$ has highly significant cross-level interactions. Lazear (1998) argued that the free-rider problem is more serious in organizations that provide a team compensation scheme. Karau and Wlliams (1993) suggested that teamwork may reduce an individual's working motivation and lead to social loafing. The negative coefficient for interactions indicates that the presence of a team compensation scheme in a branch unit strengthens the effect on others' performance $(O Y)$. In other words, if $O Y$ increases, individual performance will decrease by 25.5 per cent (NT\$ 32,130). However, with a team compensation scheme, an individual's performance will decrease by more than 25.5 per cent and up to 34.1 per cent (25.5 per cent + 8.6 per cent). Overall, although $S I Z E_{j}$ and $G B O N_{j}$ do not directly affect an individual's performance, the impact of others' performances on an individual's performance can be adjusted in terms of cross-level interactions. In addition, the estimated results of Model 3 suggest that the variations of $u_{0 j}, u_{4 j}, u_{6 j}$, and $u_{7 j}$, are significant, indicating that the intercepts and the three slopes $\left(\Upsilon_{40}, \Upsilon_{60}\right.$, and $\gamma_{70}$ ) contain random components and that other important branch-level characteristic variables have not been considered.

To further review the moderating effect of the number of agents and team compensation, this paper focuses on the top and bottom 25 per cent according to the number of agents. The average performance by others is added with two standard deviations in order to determine the impact of a peer's average performance on another individual's performance in large and small branches, and between branches that do or do not utilize team compensation. As shown in Figures 2 and 3, having a greater number of agents or providing a team compensation scheme strengthens the relationship between average peer performance and an individual's performance. In contrast, having fewer agents or not providing a team compensation scheme weakens the relationship between average peer performance and an individual's performance.

Another important aspect of model specification and testing is examining how closely the model fits the data. Deviance is a measure of the lack of fit between the data and the model. The deviance for any one model cannot be interpreted directly, but it can be used to compare multiple models among each other. The difference in deviance between each model is distributed as a chi-square statistic with degrees of freedom equal to the difference in the number of parameters estimated in each model. For example, considering Table 3, the deviance for model 1 is 427.961 , while the deviance for model 2 is -147.350 . The difference between these two deviances is 575.311, which is compared to a chi-square distribution with 42 df (45 parameters-3 parameters). The difference is significant; so there is evidence that Model 2 fits the data 
better than Model 1. Additionally, Model 3 is significantly better than Model $2\left(\Delta \chi^{2}=7.613\right.$, $d f=4$, p-value close to 10 per cent level of significance).
Figure 2

The moderate effect of the SIZE

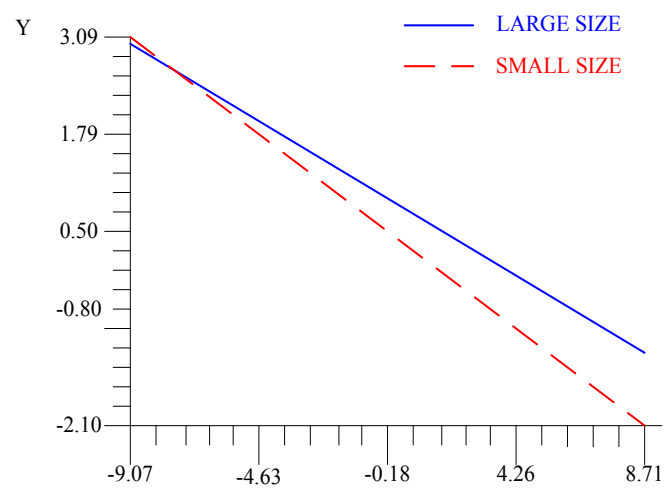

OY

\subsection{OLS estimation results}

For purposes of comparison, Table 3 presents the OLS estimates for this model. Using Model 3 intercepts and slopes as outcomes, this paper conducts an OLS estimation. The results suggest that the estimated OLS error $\left(r_{i}\right)$ variation is 0.062 , which is higher than the 0.020 of Model 3 . Coefficients relating to the branch characteristic variables $\left(\Upsilon_{01}, \Upsilon_{02}, \Upsilon_{41}\right.$, and $\left.\Upsilon_{42}\right)$ have all been underestimated, thus verifying the findings by Raudenbush and Bryk (2002). If the OLS violates the assumption of the regression model's residual independence, it will result in an over-estimation of the error

\section{Figure 3}

The moderate effect of the GBON

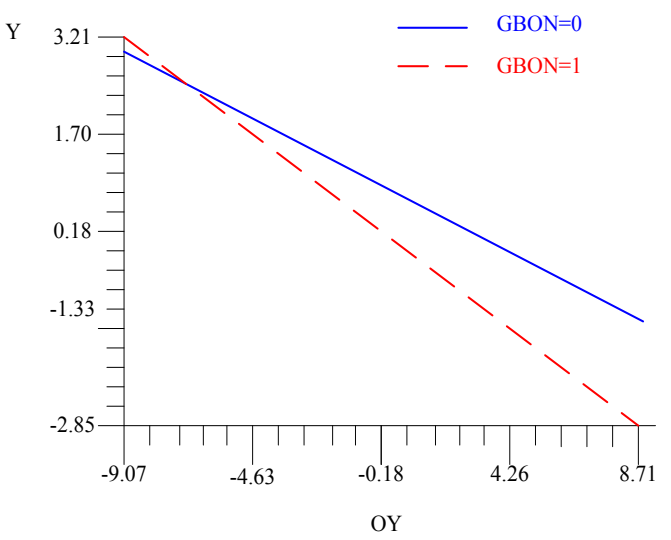

variance and an underestimation of the regression coefficient standard error. This result also shows that the OLS and Model 3 estimates differ substantially for several parameters. For example, the OLS IHOUR coefficient $\gamma_{30}$, has reached the 5 per cent significance level. It is even more noteworthy that the coefficient of $O Y \Upsilon_{40}$ is 0.020 , thereby reaching the 5 per cent significance level. The estimation result is different from the sign of Model 3. Regarding the model fitness, the comparison of the AIC or BIC implies that the Model 3 intercepts and slopes model provides a much better fit.

Table 3

Empirical results and analysis

\begin{tabular}{|c|c|c|c|c|}
\hline Model & Model 1 & Model 2 & Model 3 & OLS \\
\hline$Y_{00}$ & $\begin{array}{c}0.9485 \\
(0.0203)^{\star *}\end{array}$ & $\begin{array}{c}0.4812 \\
(0.1897)^{\star \star}\end{array}$ & $\begin{array}{c}0.6157 \\
(0.2160)^{\star \star}\end{array}$ & $\begin{array}{c}0.7309 \\
(0.0220)^{\star *}\end{array}$ \\
\hline GENDER $\Upsilon_{10}$ & & $\begin{array}{c}0.0143 \\
(0.0132) \\
\end{array}$ & $\begin{array}{c}0.0143 \\
(0.0131)\end{array}$ & $\begin{array}{c}0.0078 \\
(0.0178) \\
\end{array}$ \\
\hline EDUCATION $\Upsilon_{20}$ & & $\begin{array}{c}0.0032 \\
(0.0148)\end{array}$ & $\begin{array}{c}0.0022 \\
(0.0152)\end{array}$ & $\begin{array}{c}0.0001 \\
(0.0267)\end{array}$ \\
\hline IHOUR $Y_{30}$ & & $\begin{array}{c}0.0045 \\
(0.0036)\end{array}$ & $\begin{array}{c}0.0041 \\
(0.0035)\end{array}$ & $\begin{array}{c}0.0146 \\
(0.0055)^{\star *}\end{array}$ \\
\hline$O Y Y_{40}$ & & $\begin{array}{c}-0.2718 \\
(0.0197)^{\star *}\end{array}$ & $\begin{array}{c}-0.2549 \\
(0.0195)^{\star *}\end{array}$ & $\begin{array}{c}0.0197 \\
(0.0044)^{\star *}\end{array}$ \\
\hline HOY Y50 & & $\begin{array}{c}0.1775 \\
(0.0236)^{* *}\end{array}$ & $\begin{array}{c}0.1724 \\
(0.0242)^{\star \star}\end{array}$ & $\begin{array}{c}0.5330 \\
(0.0289)^{\star *}\end{array}$ \\
\hline
\end{tabular}




\begin{tabular}{|c|c|c|c|c|}
\hline Model & Model 1 & Model 2 & Model 3 & OLS \\
\hline$W E X P \quad Y_{60}$ & & $\begin{array}{c}0.0130 \\
(0.0052)^{\star *}\end{array}$ & $\begin{array}{c}0.0136 \\
(0.0051)^{\star *}\end{array}$ & $\begin{array}{c}0.0097 \\
(0.0059) \\
\end{array}$ \\
\hline SWEXP $\quad \Upsilon_{70}$ & & $\begin{array}{l}-0.0005 \\
(0.0003)^{*}\end{array}$ & $\begin{array}{c}-0.0005 \\
(0.0002)^{\star *}\end{array}$ & $\begin{array}{l}-0.0003 \\
(0.0002)\end{array}$ \\
\hline$S I Z E_{j} Y_{01}$ & & & $\begin{array}{l}-0.0302 \\
(0.0276)\end{array}$ & $\begin{array}{c}0.0008 \\
(0.0020)\end{array}$ \\
\hline$G B O N_{j} \Upsilon_{02}$ & & & $\begin{array}{l}-0.5770 \\
(0.4174)\end{array}$ & $\begin{array}{l}-0.0156 \\
(0.0390)\end{array}$ \\
\hline$S I X E_{j} \times O Y Y_{41}$ & & & $\begin{array}{c}-0.0043 \\
(0.0019)^{\star *}\end{array}$ & $\begin{array}{l}-0.0001 \\
(0.0004)\end{array}$ \\
\hline$G B O N_{j}$ × $O Y Y_{42}$ & & & $\begin{array}{l}-0.0860 \\
(0.0348)^{* *}\end{array}$ & $\begin{array}{c}0.0038 \\
(0.0104)\end{array}$ \\
\hline$u_{\mathrm{o} j}$ & $\begin{array}{c}0.0075 \\
(77.0954)^{* *}\end{array}$ & $\begin{array}{c}1.6109 \\
(224.4189)^{\star \star}\end{array}$ & $\begin{array}{c}1.6186 \\
(325.6178)^{\star *}\end{array}$ & \\
\hline$u_{1 j}$ & & $\begin{array}{c}0.0018 \\
(6.2409)\end{array}$ & $\begin{array}{c}0.0017 \\
(6.2844)\end{array}$ & \\
\hline$u_{2 j}$ & & $\begin{array}{c}0.0020 \\
(18.3846)\end{array}$ & $\begin{array}{c}0.0025 \\
(18.5178)\end{array}$ & \\
\hline$u_{3 j}$ & & $\begin{array}{c}0.0002 \\
(12.6392)\end{array}$ & $\begin{array}{c}0.0002 \\
(12.6188)\end{array}$ & \\
\hline$u_{4 j}$ & & $\begin{array}{c}0.0101 \\
(23.5186)^{\star \star}\end{array}$ & $\begin{array}{c}0.0100 \\
(28.2878)^{\star \star}\end{array}$ & \\
\hline$u_{5 j}$ & & $\begin{array}{c}0.0069 \\
(18.2886)\end{array}$ & $\begin{array}{c}0.0088 \\
(18.2310)\end{array}$ & \\
\hline$u_{6 j}$ & & $\begin{array}{c}0.0005 \\
(39.0383)^{\star *}\end{array}$ & $\begin{array}{c}0.0004 \\
(39.2152)^{\star \star}\end{array}$ & \\
\hline$u_{7 j}$ & & $\begin{array}{c}0.0001 \\
(37.5001)^{\star \star}\end{array}$ & $\begin{array}{c}0.0001 \\
(37.7128)^{\star *}\end{array}$ & \\
\hline$r_{i j}$ & 0.1279 & 0.0202 & 0.0200 & \\
\hline$r_{i}$ & & & & 0.0620 \\
\hline Deviance & 427.9610 & -147.3501 & -154.9628 & 29.4409 \\
\hline $\begin{array}{l}\text { Number of estimated } \\
\text { parameters }\end{array}$ & 3 & 45 & 49 & 13 \\
\hline$A I C$ & 433.961 & -57.350 & -56.963 & 11.280 \\
\hline$B I C$ & 436.104 & -25.205 & -21.961 & 20.566 \\
\hline
\end{tabular}

Notes: ${ }^{*} p<0.10,{ }^{* *} p<0.05$. Regarding the fixed effect part, the content inside the () is the robust standard errors; regarding the random effect parts, the content inside the () is the value of $\chi^{2}$.

6

\section{Conclusions and suggestions}

With real estate agents as the object of analysis, this paper examines whether the average performance by others (i.e., the peer competition threat) has a negative impact on individual performance; whether more agents or a team compensation scheme lead to lower individual performances; and, in a branch with more agents or a team compensation scheme, whether the individual's performance will be greater owing to the marginal effect of the average performance by others.

\subsection{Theoretical implications}

The empirical results suggest that the variation of an individual's performance is significant among different branches. The average performance by others has a significant negative impact on an individual's performance, as expected. Kandel and Lazear (1992) used "the average performance of others" to represent a positive impact on individuals that can inspire working incentives while leaving out nasty peer competition. However, this claim is dubious. The housing brokerage industry emphasizes individual performance, which thus implies the existence a peer competition threat (which has been confirmed in this study).

In branches with more "agents" or with a "team compensation scheme", the impact of the average performance of others on an individual's performance is significantly higher than it is in branches with fewer "agents" or without a "team compensation scheme", as 
expected. In other words, more agents in the branch would strengthen the negative impact of peer competition threat on an individual's performance, implying that the peer competition will be fiercer in cases of limited resources. The results of this model show that $G B O N_{j}$ has highly significant cross-level interactions. The negative coefficient for the interactions indicates that the presence of a team compensation scheme in a branch unit acts to strengthen the effect of others' performance $(O Y)$.

In terms of theory, setting the individual level and branch level of the model can distinguish individual conditions and branch characteristics relating to individual performance contributions. In this study, the model was not only set for the team compensation scheme and the number of agents across the levels directly affecting individual performance, but also took into account the team compensation scheme and the number of agents across levels moderately affecting the others' performance. Further, the coefficient of each variable can be random, i.e., coefficients between the various branches are not fixed. The empirical results also show that the performance of others, work experience and work experience squared really are random, so the model can be made more flexible based on the theoretical construct.

This study's findings can help to elucidate the impact of a peer competition threat on an individual's performance, as well as whether relevant theories can be tested with actual data. The empirical results of this study also suggest that the interactive relationship between working team members and the impact of peer competition threat are topics that merit further exploration.

\subsection{Practical implications}

This paper concludes that men's performance is not significantly higher than women's performance among housing brokerage agents in Kaohsiung, Taiwan. A higher educational level reflects ample knowledge and better performance. However, the empirical results suggest that educational level has no significant impact on agent performance. Regarding daily hours worked, longer daily working hours result in a higher level of effort and better job performance. The daily number of hours worked has no significant impact on agent performance. The empirical results suggest that increased work experience can improve an individual's performance. According to the empirical results, if the realtor brokers want to enhance individual performance, thereby increasing team performance, they should consider selecting those with experience in the brokerage industry as a priority. This has been reflected in the actual market operation in Taiwan. The brokers of the direct sales system emphasize brand image with certain requirements, including college education and lack of experience in the brokerage industry to facilitate the hiring and development of new employees consistent with each company's corporate image. However, brokers of the franchise system emphasize the improvement of individual performance. In most cases, they prefer to hire those with experience in the brokerage industry to minimize educational/training costs and to win profits for the company within a short period of time.

\subsection{Limitations and future research}

Regarding the limitations of this study, as the research subjects are large chain realtor brokers, the research findings cannot represent numerous independent agencies. Second, the data source of this study was a questionnaire survey, and the variables, such as business performance, may include measurement errors. If future studies can obtain human resource data from the brokerage companies themselves, the data collected regarding agents' business performance will be more accurate, which in turn could allow for improvement upon these research findings.

This study could be extended in several different directions in the future. First, the intercepts and some of the slopes have random components, suggesting other important branchlevel characteristic variables that should be considered. In the future, other important characteristic variables may be included in the model for consideration and estimation. Moreover, the impact of peer competition on performance may vary over time. This study adopts a cross-section data analysis approach and is unable to address this problem until further studies are conducted. 


\section{Endnotes}

1 As observed above, many of these research findings are consistent. For example, the number of hours worked, experience, licensing and education all have positive effects on an agent's income. Abelson, Kacmar and Jackofsky (1990), Sirmans and Swicegood (1997), and Sirmans and Swicegood (2000) also found a positive relationship between nonpecuniary factors, such as job satisfaction and agent performance. However, owing to different sampling techniques, many influencing factors could lead to inconsistent results among different studies. In particular, conflicting results often occur in terms of gender, race, franchise affiliation, and the agent's age.

2 The question in the questionnaire is as follows: "speaking from your experience, when you and your workmates learn about the same business case, have your workmates ever competed with you to win the case? (1) never (2) sometimes (3) frequently". A total of 233 respondents answered "never" ( 45 per cent), 238 respondents answered "sometimes" (45.9 per cent), and 47 respondents answered "frequently" (9.1 per cent). Respondents who provided one of the latter two answers accounted for 55 per cent.

3 Knez and Simester (2001) inferred that the lack of a free-rider effect has resulted in the standardized internal working procedures of the airline. Employees may easily supervise each other, resulting in the non-existence of the free-rider effect.

4 Detailed questionnaire items are available upon request.

5 Rubin and Perloff (1993) and Booth and Frank (1999) used "income" as the proxy variable for performance or productivity. However, income reflects the level of performance as well as the employer's salary structure. Therefore, it cannot entirely reflect the level of "performance." Using sales performance as the proxy variable for the sales personnel's performance or productivity may result in lower measurement error when compared to other proxy variables (e.g., income).

6 For example, if the monthly sales performance is NT\$3,000,000 for the last three months, and the commission rate is 6 per cent, then the performance will be NT\$18,000.

7 Peer attacks are common among building companies and landlords, housing agents and homeowners, and among real estate agents. Peers often strive to achieve their company or personal interests by achieving larger profits, reducing service fees and striving to obtain cases (Chou, 1998, Housing Brokerage Market Transaction Practice, www.ttvs.cy.edu.tw/practice/work9/)

\section{References}

ABELSON, M.A., KACMAR, K.M. \& JACKOFSKY, E.F. 1990. Factors influencing real estate brokerage sales staff performance. Journal of Real Estate Research, 5(2):265-276.

ANDERSON, R.I., BYRD, A.K. \& HURST, M.E. 2012. Earnings of real estate salespersons with prior work experience. Journal of Housing Research, 21(1):83-99.

ARMSTRONG, J.S. \& OVERTON, T.S. 1977. Estimating nonresponse bias in mail surveys. Journal of Marketing Research, 14:396-402.

BABCOCK, P., BEDARD, K., CHARNESS, G., HARTMAN, J. \& ROYER, H. 2012. Letting down the team? Evidence of social effects of team incentives. Working Paper UCSB.

BARON, J.N. \& KREPS, D.M. 1999. Strategic human resources: Frame-works for general managers. New York: John Wiley \& Sons Inc.

BENJAMIN, J.D., JUD, G.D. \& SIRMANS, G.S. 2000. What do we know about real estate brokerage? The Journal of Real Estate Research, 20(1):5-30.

BOOTH, A.L. \& FRANK, J. 1999. Earnings, productivity, and performance-related pay. Journal of Labor Economics, 17:447-463.

CASE, A.C. \& KATZ, L.F. 1991. The company you keep: The effects of family and neighborhood on disadvantaged youths. NBER Working Paper no.3705.

CHOU, J.C. 1998. Housing brokerage market transaction practice. Available at: www.ttvs.cy.edu.tw/ practice/work9/ [accessed 2012-12-07].

COHEN, J. 1988. Statistical power analysis for the behavioral sciences. Lawrence Erlbaum Associates, New Jersey.

CORGNET, B., HERNAN-GONZALEZ, R. \& RASSENTI, S. 2013. Peer pressure and moral hazard in teams: Experimental evidence. Economic Science Institute, Chapman University Working Paper 11-05. CRELLIN, G.E., FREW, J.R. \& JUD, G.D. 1988. The earnings of realtors: Some empirical evidence. Journal of Real Estate Research, 3(2):69-78.

DRAGO. R. \& GARVEY, G.T. 1998. Incentives for helping on the job: Theory and evidence. Journal of Labor Economics, 16:1-25.

EVANS, W.N., OATES, W.E. \& SCHWAB, R.M. 1992. Measuring peer group effects: A study of teenage behavior. Journal of Political Economy, 100:966-991.

FOLLAIN, J.R., LUTES, T. \& MEIER, D.A. 1987. Why do some real estate salespeople earn more than others? Journal of Real Estate Research 2(1):73-81. Available at: http://ares.metapress.com/content/ 17t8272706664354/ [accessed 2012-06-23]. 
GLOWER, M. \& HENDERSHOTT, P.H. 1988. The determinants of realtor income. Journal of Real Estate Research, 3(2):53-68.

FALK, A. \& ICHINO, A. 2003. Clean evidence on peer pressure. Bonn Germany IZA Discussion Paper, no. 732.

GAVIRIA, A. \& RAPHAEL, S. 2001. School-based peer effects and juvenile behavior. Review of Economics and Statistics, 83:257-268.

JANHONEN, M. \& JOHANSON, J.E. 2011. Role of knowledge conversion and social networks in team performance. International Journal of Information Management, 31(3):217-225.

JUD, G.D. \& WINKLER, D.T. 1998. The earnings of real estate salespersons and others in the financial services industry. Journal of Real Estate Finance and Economics, 17(3):279-291.

KANDEL, E. \& LAZEAR, E.P. 1992. Peer pressure and partnerships. Journal of Political Economy, 100:801-817.

KARAU, S.J. \& WILLIAMS, K.D. 1993. Social loafing: A meta-analytic review and theoretical integration. Journal of Personality and Social Psychology, 65(4):681-706.

KNEZ, M. \& SIMESTER, D. 2001. Firm-wide incentives and mutual monitoring at continental airlines. Journal of Labor Economics, 19(4):743-772.

LAZEAR, E.P. 1998. Personnel economics for managers. New York: John Wiley \& Sons.

LAZEAR, E.P. 1999. Personnel economics: Past lessons and future directions. Journal of Labor Economics, 17:199-236.

LAZEAR, E.P. 2000. Performance pay and productivity. American Economic Review, 5:1346-1361.

LEE, C.C., YOU, S.M. \& SHEN, P.C. 2010. Using an ordered probit regression model to assess the performance of real estate brokers. Journal of International Management Studies, 5(2):168-175.

LEE, C.C. 2012. The impact of compensation schemes on housing agent performance, International Journal of Asian Social Science, 2:2150-2161.

MCEWAN, P.J. 2003. Peer effect on student achievement: Evidence from Chile. Economics of Education Review, 22:131-141.

MINCER, J. 1970. The distribution of labour incomes: A survey with special reference to the human capital approach. Journal of Economic Literature, 8:1-26.

MINCER, J. 1974. Schooling, experience, and earnings. National Bureau of Economic Research Inc., Madison Ave, New York.

MINCER, J. \& POLACHEK, S. 1974. Family investment in human capital: Earnings of women. Journal of Political Economy, 82:S76-S108.

MOSSHOLDER, K.W., RICHARDSON, H.A. \& SETTOON, R.P. 2011. Human resource systems and helping in organizations: A relational perspective. Academy of Management Review, 36:33-52.

NORTON, E.C., LINDROOTH, R.C. \& ENNETT, S.T. 1998. Controlling for the endogeneity of peer substance use on adolescent alcohol and tobacco use. Health Economics, 7:439-453.

PAARSCH, H.J. \& SHEARER, B.S. 1999. The responses of worker effort to piece rates. Journal of Human Resources, 4:644-667.

PAARSCH, H.J. \& SHEARER, B.S. 2000. Piece rates, fixed wages, and incentive effects: Statistical evidence from payroll records. International Economic Review, 41:59-92.

RAUDENBUSH, S.W. \& BRYK, A.S. 2002. Hierarchical linear models: Applications and data analysis methods. Sage Publications Newbury Park.

RUBIN, D.K. \& PERLOFF, J.M. 1993. Who works for piece rates and why. American Journal of Agricultural Economics, 75(4):1036-1043.

SIRMANS, G.S. \& SWICEGOOD, P.G. 1997. Determinants of real estate licensee income. Journal of Real Estate Research, 14(2):137-159.

SIRMANS, G.S. \& SWICEGOOD, P.G. 2000. Determining real estate licensee income, Journal of Real Estate Research, 20(1):189-204.

YU, I.R. \& LIU, Y.S. 2004. Compensation system's incentive effect in the work team: An empirical analysis of Taiwan's realtor brokerage industry. Taiwan Economic Review, 32(4):395-416. 